\title{
A Novel Teaching Mode of Mechanical Engineering Based on Compatibility Mode of Guidance and Giving Lecture
}

\author{
Mingming Xing* \\ School of Mechanical Engineering \\ Linyi University \\ Linyi 276000, China \\ xingmingming2009@126.com
}

\author{
Lili Zhou \\ School of Chemistry \& Chemical Engineering \\ Linyi University, Linyi 276000, China \\ zhoulili@lyu.edu.cn
}

\begin{abstract}
Considering the lack of undergraduate education with the tutorial system, the new teaching mode of undergraduate education with compatibility mode of the guidance and giving lecture is proposed. In this teaching method, the advantages of tutorial system and giving lecture are absorbed. Besides, some new institutions are adopted, such as perfect evaluation system of tutor, comprehensive management system of department and incentive systems of teacher and student. In new teaching mode, the need for applied career person with ability of mechanical engineering that meets economic construction and development is considered. The mechanical engineering talent of high-level, compound, and practical knowledge is trained by the aspects of engineering practice, technological innovation, engineering design and construction, etc. The new engineering teaching system is discussed, which is beneficial to improve the innovative ability in the practice and employment competition ability, but in the meanwhile which is a theoretical reference for teaching reform.
\end{abstract}

Keywords-Undergraduate Tutorial system; Giving lecture

education; Teaching mode;

\section{INTRODUCTION}

Tutorial system derives its origin from New College, Oxford, which is established in 1380 by Bishop of Winchester William Wykeham. Professor of Will Grayburn Moore, St. John's College of Oxford, believes that there are three factors that the tutorial system is successfully used in College of Oxford, such as students' individual difference, cooperation between tutor and student and unique attitude towards the knowledge [1]. In retrospect, based on the character formation, the tutorial system plays the important role in eight hundred years of Oxford's evolution. With the rapid development of economic and cultural exchanges in the world, different universities carry out the credit system after Beijing University in 1910. However, under the influence of reforming the education system, the credit system is abandoned by different universities in 1952, and the academic year system is used. Therefore, the development of tutorial system is impeded. In 90 s of 20th century, with the implementation of the credit system in different universities, the tutorial system has a rapid development.
Based on the Chinese government's National Outline for Medium-Term and Long-Term Educational Reform and Development 2010-2020, the essential requirement of the educational work should be the talent-cultivation-oriented for universities, the strong impetus for Educational Progress should be reformed and innovated, and core task of education reform should be improved quality. Follow the wave of educational reform, there are a bit of challenges for experts and scholars, especially universities. The problems are investigated and discussed in depth, which is type of education and method of education. Li Zhiyi, a president of Dalian University of Technology, proposes that the result-oriented education reform of higher engineering education should focus on three conversions, namely, conversion from subject-oriented to target-oriented; from teacher-centered to student-centered and from quality supervision to continuous improvement [2]. Li Liguo, a professor at China Renmin University in Beijing, points out that Chinese higher education can successfully overcome the dilemma faced by developing countries in popularizing higher education and develop into a modern higher education with Chinese characteristics [3]. Qi Yeguo, a professor in East China Normal University, advises that the construction of an undergraduate teaching quality guarantee system makes a response to society's worry or doubt about undergraduate educational quality, and fully draws on methods used in quality control of industrial and commercial enterprises[4]. Li Peigen, a member of the Chinese Academy of Engineering, points out that the quality of the engineering talents can be guaranteed by the practical teaching of engineering education [5]. He makes a systematic summary on the problems present in the practical teaching of undergraduate engineering education from five aspects: the goals of practical teaching, the design of practical teaching system, the methods of practical teaching, conditions of practical teaching and the teaching staff and then the causes of these problems are explored form several perspectives, such as traditional vulture, practical teaching concepts, education mechanism, the input of educational resources, etc. He Chaoyang thinks that the inverted classroom can contribute more in students' learning autonomy, team-work commitment, creative spirit, classroom atmosphere and internalization of knowledge, which offers some reference for the higher engineering education classroom to carry out inverted classroom teaching in our country[6]. 
Zhou Guangli, a PhD supervisor of Renmin University of China, points out that the concept of scholarship of teaching is not only a powerful means for faculty evaluation, but also an important index to evaluate the core competence of university. He thinks that scholarship of teaching should be a priority in the strategy of university [7].

In recent years, the undergraduate education and reform are explored in different universities. The tutorial system of undergraduate education is a teaching method, which deals with the challenge of undergraduate education. According to the statistics, the reform of general education is carried out in Fudan school build in 2005. The training system of general education is built with core courses and college-tutorial system [8]. However, there are some troubles when the reform of general education is put into effort in Fudan University. For example, besides the teaching organization should be further improved, there are difficulties in carrying out college-tutorial system. According to a census report of the tutorial system of undergraduate education for Fuzhou University in 2012, the students' satisfaction with the tutorial system is ordinary [9]. And there are some problems, such as the ambiguity of boundaries of tutor's responsibility, the simplification of tutors' guidance method and content, and the lack of tutor evaluation systems. In conclusion, there are some problems in Undergraduates Tutorial System like shortage of tutors, unclear definition and formalism. Reforms must be done, which must lies in the development of independent thinking, the focus on instructional system, instruction through the whole process, tutor qualification and enhancement of tutorial system [10]. Guo Yong, a professor in Tsinghua University, indicates that when Chinese universities tried to pursue the college system without overall general education, they might meet great difficulties. Actually, Chinese universities needn't copy the college system. What's more important was to put more emphasis on general education in undergraduate education [8]. The current tutorial system is not an improvement of institutional level, and is a pattern exploration of the talents training. Because the seriousness and binding of institutions are scarce, the tutor will be working really casually, and it cannot obtain the expected results. Moreover, the tutorial system is window dressing in some universities. Therefore, the effect that the tutorial system is copied for undergraduate education is not ideal. The primary task is exploring new teaching methods that social responsibility, innovative spirit and practice ability of students are enhanced. For all this, in order to improve the teaching quality, the new teaching mode of undergraduate education with compatibility mode of the guidance and giving lecture is proposed based on planning for its 13th Five Year Plan in 2015.

\section{TEACHING SYSTEM WITH COMPATIBILITY MODE OF GUIDANCE AND GIVING LECTURE}

\section{A. Management responsibility of department}

1) Teaching institution of tutorial system

First, the work of tutorial system should be taken seriously by Dean's office. The work of tutorial system is equated with teaching job, and is an indicator of teachers' professional evaluation. And thus, the worker morale of tutor is motivated.
At the same time, the tutorial system will be included in the training program, and should be adopted by teaching organization and operation system. Besides, in order to reduce the burden of students and increase student independent thinking time, the total credit of talent development will be reduced.

\section{2) Construction of the tutor team}

In order to resolve source shortage of tutor team, the teacher resources of both inside and outside the universities should be integrated. Firstly, the evaluation of on-campus tutor should be selected. With selecting on-campus tutor, the responsibility and job skills are the basic requirement. The professional expertise of tutor should be a major consideration. Besides, the young tutors should be trained by the guiding ideology, guiding principles and particular skills. Secondly, the selection of out-campus tutor should be considered. In order to strengthen the practice teaching and enhance students practice manipulative ability, the practical guidance teacher and base should be selected to reinforce the plan of tutorial system. At the same time, the retired teacher and academy student are all selected to and support tutor.

\section{3) Management system}

The institution is a great treasure which earlier generations have given us. The education system of tutorial system needs a series of support system, such as the institution of tutor selection and elimination, usage and management of research funds, tutor's laboratory, credit system, evaluation system of tutor. Based on above facts, the management system should be made with advantages of each college and current policy.

\section{B. Guiding system of entire process trace}

\section{1) Research exhibition of tutor}

The research of tutor is internationally frontier topic, which is an important subject for tutor system. The schematic of research exhibition is shown in Fig.1.The purpose of research exhibition shows students some knowledge, such as the origin of the current study, the current situation and prospect of the study both at home and abroad, the relation between research subject and specialized courses and the benefit or effect of current study. With above knowledge, the enthusiasm of student is motivated. And the selection of tutor is beneficial for acquire knowledge and playing special advantage.

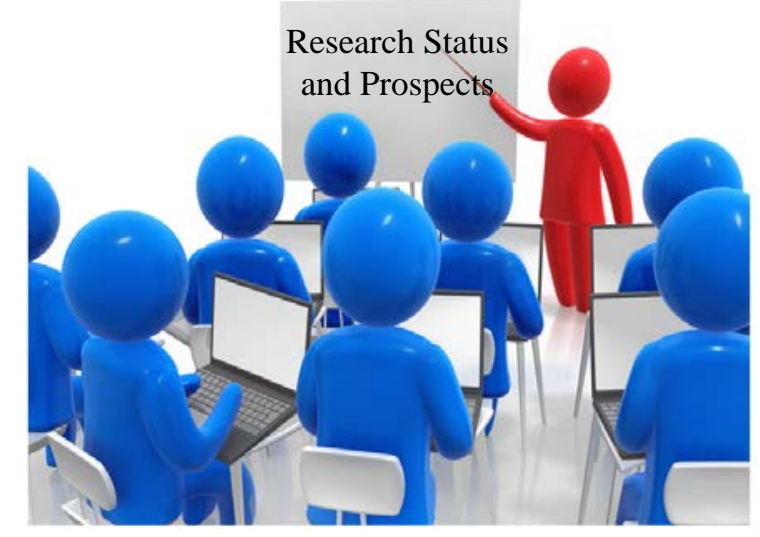

Fig. 1. The schematic of research exhibition of tutor 


\section{2) Two-way choice between tutor and student}

The spring, the day is morning. The first semester of student is an important stage of life goals in college. Therefore, the tutor should be selected firstly, and the development program should be made with direction of tutor research and professional advantage. The deadline of two-way choice is the final stage of the second term. However, considering the special situations of tutor and student, the selection can be adjusted in third term. To be true, the specialized courses and practical training will start in the third term, if the selection is changed, the course and learning process will be affected. Therefore, the third term is the last adjusting time. The schematic of two-way choice is shown in Fig.2.

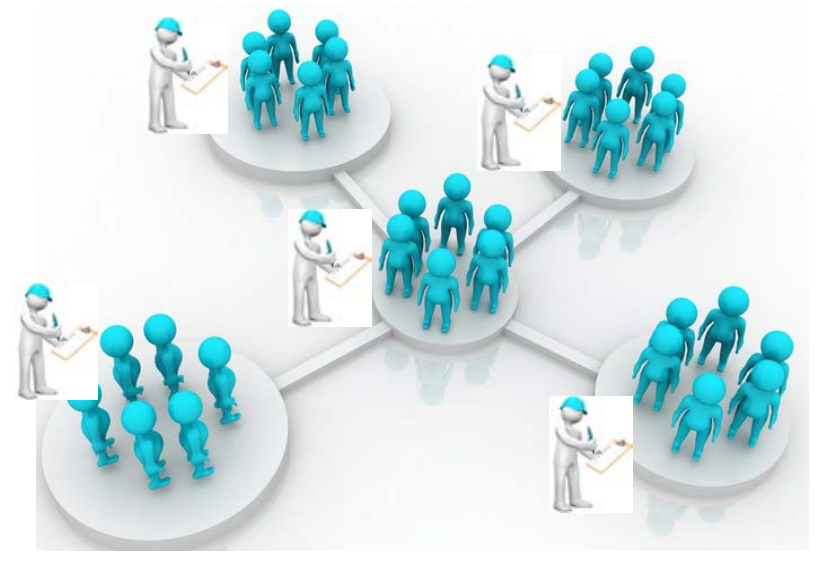

Fig. 2. The schematic of two-way choice between tutor and student

Considering the change in learning style, living environment and human-human interaction, the guidance of tutor will start as soon as possible in first term. The overall course is as follows.

\section{a) Self-cultivation education}

The self-cultivation education of freshmen and sophomore is foundation in first two years. Considering their studies and practice, the special knowledge education and comprehensive quality will be unified together by tutor. The different abilities are all obtained, such as right learning method, self-control approach, self-cultivation, professional ability. For example, based on the direction of research and specialty training plan, the professional classes are selected by tutor. The knowledge what part of professional class has relationship with research subject is known by students. The key knowledge and learning goal of a professional class is clear. And students should know that the study of computer major courses is not abstract theory and is great help to solve scientific problems.

\section{b) Improved professional education}

The improved professional education is the core of undergraduate education in the third and fourth term. After previous two years, the professional education will start at this stage. The education contents include the method of academic research, reading references, exploration of scientific questions and the problem of master candidates and job hunting. Firstly, students are guided to carry out social research related to scientific research, literature reading, data collecting, introduction to analysis software, etc. Secondly, making timetable for guidance and guidance form, which can make students more in-depth scientific research training and quality training, enhance the competitiveness of the undergraduates in further education or one's deceased father grind, and can make the students to own the spirit of thinking, exploration, seeking knowledge and researching study. Finally, in order to let students take four years of effort and sweat into results, the tutors should actively organize the student to carry on the academic papers and graduate thesis writing. At the same time, the tutors should try to encourage each student to write their own research results, and give each student specific guidance about writing methods, writing techniques, professional term, thesis editing, etc. Based on the content and the level of writing, the tutors recommend the research results published in different academic journals or patent. Graduation thesis is efforts of four years of college life, and the center of thesis research is the basic knowledge of learning and the improvement of professional academic ability. Therefore, the writing work of graduation thesis should be taken seriously. Then the tutors should guide students to study the method of academic paper writing. The tutors should take responsibility to all aspects of students, and improving students' innovation capability of scientific as well as technological competitiveness of employment.

\section{SUMMARY}

Considering the lack of the tutorial system in undergraduate education, the novel teaching method of compatibility mode of guidance and giving lecture is proposed based on the planning for its 13th Five Year Plan in 2015. This method includes the advantages of tutorial system and giving lecture. Based on the basic national conditions of undergraduate education and the time development tidal current, the teaching goal of new mode for mechanical engineering is cultivating compound talents. In the detail, the need for applied career person with ability of mechanical engineering that meets economic construction and development is considered. The mechanical engineering talent of high-level, compound, and practical knowledge is trained by the aspects of engineering practice, technological innovation, technology development, engineering design and construction and application and popularization of new technology. In this paper, the new engineering teaching system of guidance and giving lecture is given. The constructive suggestions about management responsibility of department and guiding system of entire process trace are given, which improve the technological innovation capacity and professional competitive capacity.

\section{ACKNOWLEDGEMENT}

This research was financially supported by the Starting Foundation for Linyi University (Grant NO. LYDX2016BS032).

\section{REFERENCES}

[1] W.G. Moore, The tutorial System and its future. Higher Education Quarterly, Vol 2, pp.26-30, 1968. 
[2] Z.Y. Li, H. Zhu, Z.J. Liu, et al, Guiding the Reform of Higher Engineering Education with Result-oriented Educational Ideas. Research in Higher Education of Engineering, Vol. 2, pp.29-34, 2014. (In Chinese)

[3] L.G. Li, Transition of the Popularization Mode of Chinese Higher Education. Tsinghua Journal of Education, Vol.35, pp.17-27, 2014. (In Chinese)

[4] Y.G. Qi, R.H. Dai, The Thought and Methodology for Constructing an Undergraduate Teaching Quality Guarantee System. Teacher Education Research, Vol. 19, pp.6-12, 2007. (In Chinese)

[5] P.G. Li, X.D Xu, G.S. Chen, On Practical Teaching of Undergraduate Engineering Education in China: Problems and Causes. Research in Higher Education of Engineering, Vol.3, pp.1-6, 2012. (In Chinese)

[6] C.Y. He, Y.F. Ou, Q. Cao, Inspiration of USA Universities' Inverted Classroom Teaching Model. Research in Higher Education of Engineering, Vol. 2, pp.148-161, 2014. (In Chinese)
[7] G.L. Zhou, H.Q. Ma, Scholarship of Teaching: A New Framework of Faculty Development and Evaluation. Educational Research, Vol.8, pp. 37-47, 2013. (In Chinese)

[8] Y. Guo, The Organizational Model of Undergraduate Education: From Harvard University. Journal of Higher Education, Vol. 37, pp. 64-73, 2016. (In Chinese)

[9] J.Y. Wang, Investigation and Analysis of Undergraduate Tutorial System Implementation Status-A Case Study of Fuzhou University . Forum on Contemporary Education, Vol.1, pp.41-45, 2012. (In Chinese)

[10] R.X. Yan, The Significance and Reform of Undergraduates Tutorial System. Research in Educational Development, Vol.21, pp.73-76, 2013. (In Chinese) 